\title{
Study of New Selective Reagent Acetophenone 2', 4'- Dihydroxy Semicarbazone for Extractive Spectrophotometric Determination of Vanadium
}

\author{
D. K. Yadav ${ }^{1, *}$, R.S. Lokhande ${ }^{2}$, S.M. Pitale ${ }^{1}$, S.P. Janwadkar ${ }^{1}$, P.S. Navarkar ${ }^{1}$, P.K. Rana ${ }^{1}$ \\ ${ }^{1}$ S.D.Arts, V.S. Apte Commerce, M.H. Mehta Science College, Palghar, Dist.-Thane, Maharashtra \\ ${ }^{2}$ Jaipur National University, Jaipur, Rajstan, India \\ *Corresponding author: dilip.yadav20@gmail.com
}

Received February 25, 2014; Revised March 10, 2014; Accepted March 11, 2014

\begin{abstract}
Acetophenone 2', 4'- dihydroxy semicarbazone [A24DHS], a new analytical reagent is proposed as a sensitive and selective spectrophotometric reagent for Vanadium (V). The reagent A24DHS is synthesized in the laboratory and characterized by NMR, IR and elemental analysis. A selective spectrophotometric method is presented for the trace determination of Vanadium using A24DHS as spectrophotometric reagent $\left(\lambda_{\max }=380 \mathrm{~nm}\right)$ in basic aqueous solution $(\mathrm{pH}=8.2)$. The Beer's law is obeyed in the concentration range from 1 to $5 \mathrm{ppm}$. The A24DHS forms a 1:2 yellow colored complex. The Sandell's Sensitivity is $0.0288 \mu \mathrm{g} \mathrm{cm}$ with molar absorptivity $3899.2 \mathrm{~L} \mathrm{~mol}^{-1} \mathrm{~cm}^{-1}$. The proposed method has been successfully applied to the determination of Vanadium alloys and synthetic samples. The precision and the accuracy obtained were satisfactory for its use in the concerned industry.
\end{abstract}

Keywords: vanadium, spectrophotometry, n-Butanol, Acetophenone 2', 4'-dihydroxy, semicarbazone derivative

Cite This Article: D. K. Yadav, R.S. Lokhande, S.M. Pitale, S.P. Janwadkar, P.S. Navarkar, and P.K. Rana, "Study of New Selective Reagent Acetophenone 2', 4'- Dihydroxy Semicarbazone for Extractive Spectrophotometric Determination of Vanadium.” World Journal of Analytical Chemistry, vol. 2, no. 1 (2014): 10-14. doi: 10.12691/wjac-2-1-3.

\section{Introduction}

Vanadium is a chemical element with the symbol $\mathrm{V}$ and atomic number 23. It is a hard, silvery gray, ductile and malleable transition metal. Vanadium was discovered by Andreas M.del Rio in 1801 [1,2,3].Although vanadium is an essential trace element for some creatures, a number of its compounds are toxic. Generally, higher toxicity is associated with higher oxidation state [4]. Vanadium is resistant to attack by alkalis, $\mathrm{HCl}, \mathrm{H}_{2} \mathrm{SO}_{4}$ and salt water. The metal oxidizes in air at around $660^{\circ} \mathrm{C}$ to the pentoxide $\left(\mathrm{V}_{2} \mathrm{O}_{5}\right)$ [5]. The main use of vanadium is in alloys. Vanadium in small amount gives strength, toughness and heat resistance to the alloys. Ferrovanadium is the most used vanadium alloy in the industry [6]. Vanadium steel used in gears. TAV (Ti-Al-V) alloy is used in jet engines and for high speed aircraft. $\mathrm{V}_{2} \mathrm{O}_{5}$ is used in ceramics and as a catalyst for the production of $\mathrm{H}_{2} \mathrm{SO}_{4}$. Vanadium plays a very limited role in biology, and is more important in ocean environments than on land. Organobromine compounds in a number of species of marine algae are generated by the action of a vanadium dependent bromoperoxidase. This is a haloperoxidase in algae which requires bromide and is an absolutely vanadiumdependent enzyme. Most organobromine compounds in the sea ultimately arise via the action of this vanadium bromoperoxidase.

Many methods have been reported for the determination of vanadium such as inductively coupled plasma atomic emission or netron activational analysis which requires expensive instruments and well-trained operators. Some of the reagents used for the spectrophotometric determination of vanadium are Formaldehyde oxime [7], 8-Quinolinol [8]. However, most of these methods suffer from certain limitation, such as interference by number of ions, of low sensitivity. The purpose of this work is to find selective, sensitive, simple method for exact determination of vanadium by using new analytical reagent. In this paper a new method has been developed using Acetophenone 2', 4'- dihydroxy semicarbazone [A24DHS] for extraction and spectrophotometric determination of vanadium, which is simple, selective and sensitive.

\section{Material and Methods}

The $\mathrm{pH}$ measurements were made using a $\mathrm{pH}$ meter Elico, Model LI-129, India in conjugation with a combined glass and calomel electrode. Shimadzu UVVisible 2100 spectrophotometer with $1.0 \mathrm{~cm}$ matched quartz cells were used for all absorbance measurements. 


\subsection{Reagent and Chemicals}

$0.1 \%$ Acetophenone 2', 4'- dihydroxy semicarbazone is prepared by dissolving the requisite amount of it in a known volume of methanol. All chemicals used were of analytical-reagent grade or the highest purity available in market (MERCK). Doubly distilled de-ionized water and analytical-reagent grade methanol, which is were used throughout. Solvents are purified by methods given by Wilfred L. E Armarego, et.al. [9].

\subsection{Synthesis of the Reagent}

\section{Acetophenone 2', 4' - dihydroxy semicarbazone (A24DHS)}

Synthesis of A24DHS involves two steps.

a. Conversion of Resorcinol to 2', 4'-Dihydroxy acetophenone [10].

b. Synthesis of semicarbazone derivative of 2',4'dihydroxy acetophenone [11].

\section{a) Conversion of Resorcinol to 2, 4-Dihydroxy}

\section{acetophenone}

Freshly fused and powdered Zinc chloride $(0.24 \mathrm{~mol}$ $\mathrm{ZnCl}_{2}$ ) is dissolved in glacial acetic acid (32 mL) by heating in a beaker on a sand bath. Dry Resorcinol $(0.2$ mol) is added with stirring to the mixture at $140^{\circ} \mathrm{C}$. The solution is heated until it just begins to boil and then kept for $20 \mathrm{~min}$. at $150^{\circ} \mathrm{C}$. Dilute hydrochloric acid $(1: 1)$ is added to the hot mixture and solution cooled $\left(5^{\circ} \mathrm{C}\right)$. The separate product is filtered and washed with dilute hydrochloric acid (1:3). It is recrystallize from hot water containing little hydrochloric acid. Melting point is $142^{\circ} \mathrm{C}$. Yield is 84.45 \%. (Scheme 1)

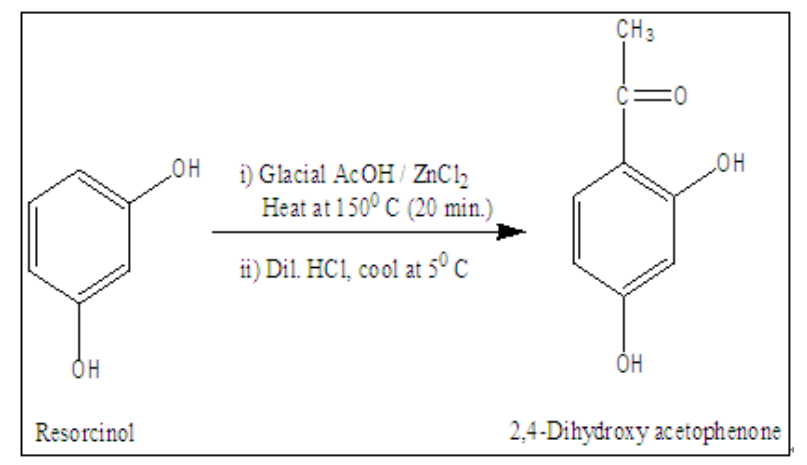

Scheme 1. Conversion of Resorcinol to 2', 4'-Dihydroxy acetophenone

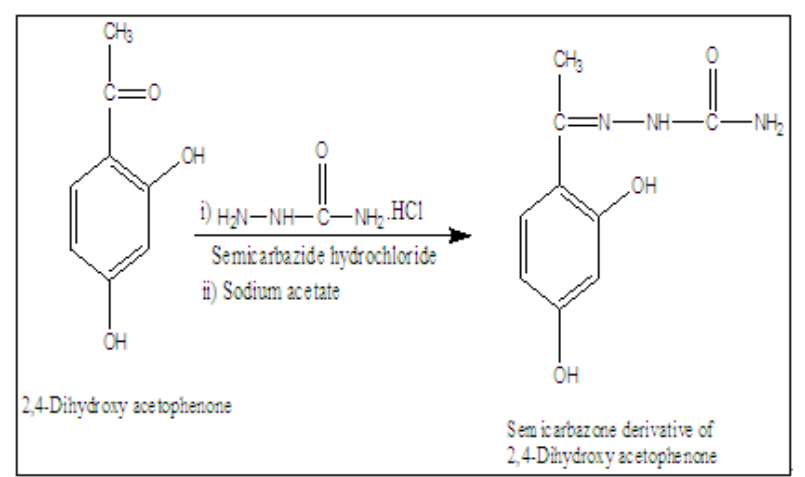

Scheme 2. Synthesis of semicarbazone derivative of 2', 4'- dihydroxy acetophenone

b) Synthesis of semicarbazone derivative of 2', 5'dihydroxy acetophenone
Equimolar mixture of sodium acetate and semicarbazide hydrochloride is dissolved in minimum quantity of water and then it is added to methanolic solution of 2', 4'-Dihydroxy acetophenone. After addition solution was warmed and stir about one hour. The pink colored compound is precipitated, washed and then recrystallized using $50 \%$ ethyl alcohol as solvent. (Scheme 2)

\subsection{V (V) Standard Solutions}

The stock solution of pentavalent vanadium was prepared by dissolving weighed amount of ammonium metavanadate in doubly distilled de-ionized water containing 1-2 $\mathrm{mL}$ of ammonia. More dilute standard solutions were prepared from this stock solution as and when required.

\subsection{Procedure for the Extraction}

$1 \mathrm{~mL}$ of aqueous solution containing $5 \mu \mathrm{g}$ of Vanadium metal and $2 \mathrm{~mL}$ of Acetophenone 2', 4'- dihydroxy semicarbazone was mixed in a $50 \mathrm{~mL}$ beaker. The $\mathrm{pH}$ of the solution was adjusted to 8.2. It must be noted that the total volume should not exceed $10 \mathrm{~mL}$. The solution was transferred to $100 \mathrm{~mL}$ separatory funnel. The beaker was washed twice with n-Butanol and transferred to the same funnel. The two phases were shaken for two minutes and allowed to separate. The organic phase was passed through anhydrous sodium sulphate in order to absorb trace amount of water from organic phase and then collected in $10 \mathrm{~mL}$ measuring flask and made up to the mark with organic solvent if required. The amount of vanadium present in the organic phase was determined quantitatively by spectrophotometric method at wavelength $380 \mathrm{~nm}$. In the aqueous phase vanadium concentration was determined by phosphotungstovanadate method [12].

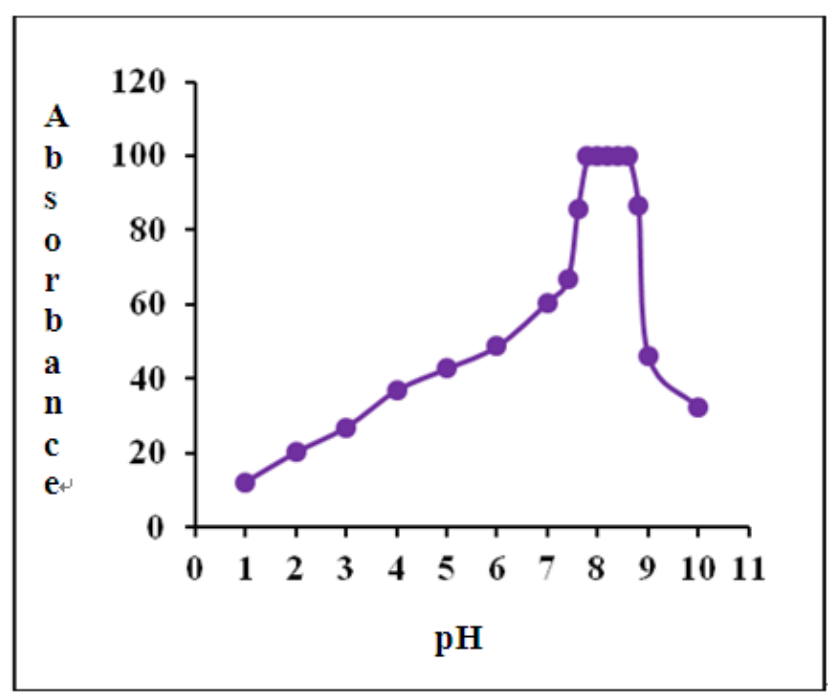

Figure 1. effect of ph on the extraction of v (v)-a24dhs complex

\section{Results and Discussion}

\section{A. Extraction as a function of $\mathbf{p H}$}

The extraction of vanadium with Acetophenone 2', 4'dihydroxy semicarbazone has been studied in the $\mathrm{pH}$ 
range 1-10 and it was observed that maximum percentage extraction of vanadium (V) is obtained at $\mathrm{pH}$ range 7.8-8.6 (Figure 1).

\section{B. Absorption spectrum}

The absorption spectrum of $\mathrm{V}(\mathrm{V})$ : A24DHS in $\mathrm{n}$ Butanol shows the maximum absorption at $380 \mathrm{~nm}$. The absorption due to reagent at this wavelength is nearly negligible. Hence the absorption measurements were carried out at $380 \mathrm{~nm}$ (Figure 2).

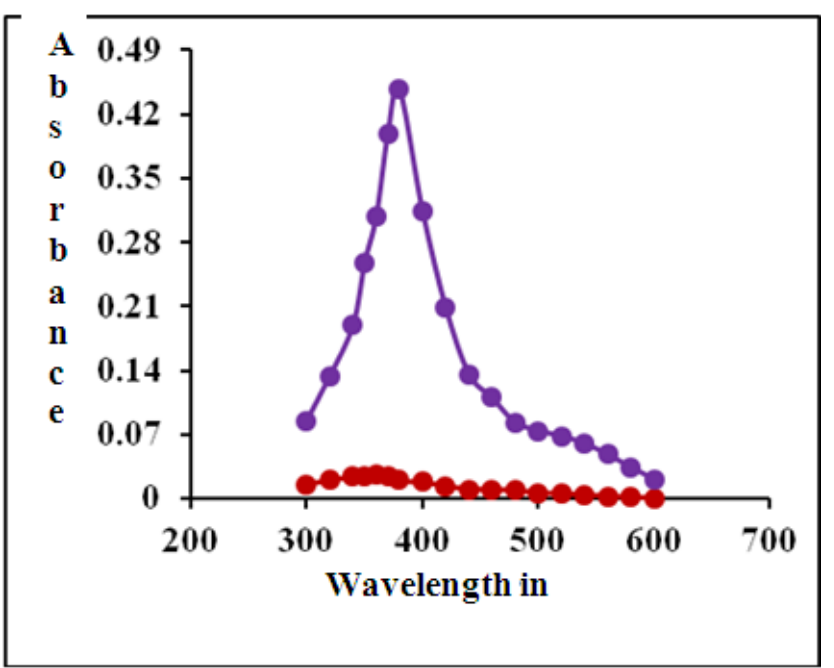

Figure 2. absorption spectrum for v - a24dhs complex

\section{Influence of diluents}

The suitability of solvent was investigated using various organic solvents and the extraction of $\mathrm{V}(\mathrm{V})$ : A24DHS was quantitative in n-Butanol. Hence, n-Butanol was used for further extraction studies as it gave better and quicker phase separation.

Table 1. Observation table for effect of various solvents on $v$ (v)a24dhs complex

\begin{tabular}{|c|c|}
\hline Solvent & \% Extraction \\
\hline Nitro benzene & 55.00 \\
\hline Diethyl ether & 59.00 \\
\hline Cyclohexanone & 51.29 \\
\hline Chloroform & 68.23 \\
\hline Hexane & 80.00 \\
\hline n-Butanol & 99.96 \\
\hline Ethyl acetate & 77.56 \\
\hline Toluene & 65.45 \\
\hline CCl $_{4}$ & 63.22 \\
\hline Xylene & 48.31 \\
\hline Isoamyl alcohol & 30.23 \\
\hline
\end{tabular}

\section{Effect of reagent concentration}

It was found that $2 \mathrm{~mL}$ of $0.1 \%$ reagent is sufficient for the color development of the metal $\mathrm{V}(\mathrm{V})$ in $10 \mathrm{~mL}$ of aqueous solution at $\mathrm{pH} 8.2$

\section{E. Effect of equilibration time and stability of the complex}

The equilibration time of 1 minute is sufficient for the quantitative extraction of vanadium. The stability of color of the $\mathrm{V}(\mathrm{V})$ : A24DHS complex with respect to time shows that the absorbance due to extracted species is stable up to 35 hours, after which slight decrease in absorbance is observed.

\section{F. Calibration plot}

The Beer's law is obeyed from 1 to $5 \mathrm{ppm}$. The molar absorptivity and sandell's sensitivity were calculated as $0.0288 \mu \mathrm{g} \mathrm{cm}^{-2}$ with molar absorptivity 3899.2 $\mathrm{L} \mathrm{mol}^{-1} \mathrm{~cm}$ -1 . (Figure 3)

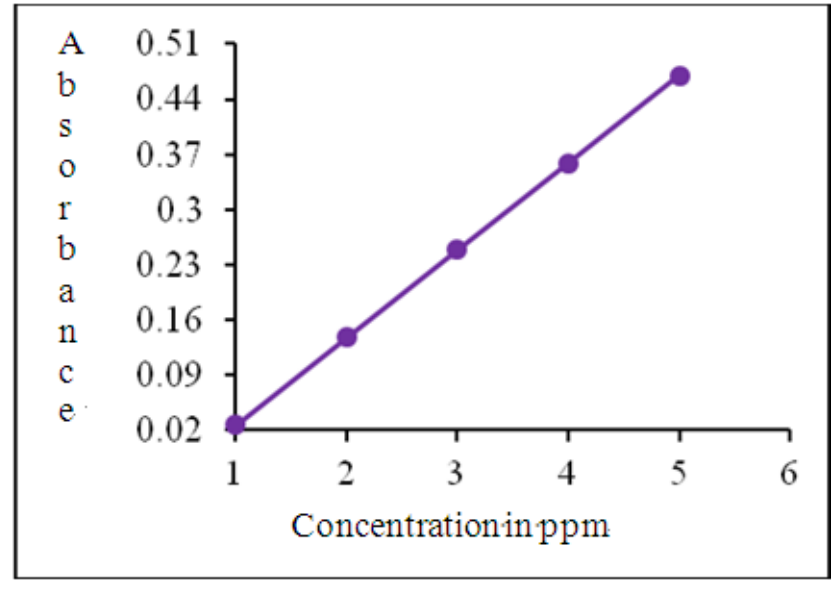

Figure 3. Calibration Plot Of V (V) - A24dhs Complex

\section{G. Limit Of Detection}

The detection limit is the smallest concentration that can be reported with a certain level of confidence. Every analytical technique has a detection limit. For methods that employ a calibration curve, the detection limit is defined as the analyte concentration yielding a response of a confidence factor $\mathrm{k}$ higher than the standard deviation of the blank $\left(\mathrm{S}_{\mathrm{b}}\right)$, as given by equation,

$$
L O D=\frac{k S_{b}}{m}
$$

Where, $m$ is the calibration sensitivity. Usually, the factor $\mathrm{k}$ chosen to be 2 or 3 . A $\mathrm{k}$ value of 2 corresponds to a confidence level of $92.1 \%$. While, a $k$ value of 3 corresponds to a 98.3\% confidence level [13]. Limit Of Detection of the present method was calculating at $98.3 \%$ confidence level, it was $0.455 \mu \mathrm{g} / \mathrm{mL}$.

\begin{tabular}{|c|c|c|}
\hline Sr. No. & Ions & Tolerance ratio \\
\hline 1 & $\mathrm{Cl}^{-1}$ & $1: 41$ \\
\hline 2 & $\mathrm{ClO}_{3}{ }^{-1}$ & $1: 21$ \\
\hline 3 & $\mathrm{IO}_{3}^{-1}$ & $1: 24$ \\
\hline 4 & $\mathrm{NO}_{2}{ }^{-1}$ & $1: 25$ \\
\hline 5 & $\mathrm{NO}_{3}^{-1}$ & $1: 16$ \\
\hline 6 & Oxalate & $1: 14$ \\
\hline 7 & $\mathrm{SO}_{4}^{-2}$ & $1: 33$ \\
\hline 8 & Tartarate & $1: 23$ \\
\hline 9 & $\mathrm{Al}^{+3}$ & $1: 16$ \\
\hline 10 & $\mathrm{~Pb}^{+2}$ & $1: 27$ \\
\hline 11 & $\mathrm{Bi}^{+2}$ & $1: 25$ \\
\hline 12 & $\mathrm{As}^{+3}$ & $1: 27$ \\
\hline 13 & $\mathrm{~W}^{+2}$ & $1: 35$ \\
\hline 14 & $\mathrm{Th}^{+4}$ & $1: 37$ \\
\hline 15 & $\mathrm{Zn}^{+2}$ & $1: 25$ \\
\hline 16 & $\mathrm{Ag}^{+1}$ & $1: 27$ \\
\hline 17 & $\mathrm{Ni}^{2+}$ & $1: 38$ \\
\hline 18 & $\mathrm{Al}^{+3}$ & $1: 16$ \\
\hline 19 & $\mathrm{~Pb}^{+2}$ & $1: 27$ \\
\hline 20 & $\mathrm{CN}^{-1}$ & Masked \\
\hline 21 & EDTA & Masked \\
\hline 22 & $\mathrm{Fe}^{3+}$ & Masked \\
\hline 23 & $\mathrm{Mo}^{6+}$ & Masked \\
\hline 24 & $\mathrm{Ti}^{4+}$ & Masked \\
\hline 25 & $\mathrm{Cu}^{+2}$ & Masked \\
\hline 26 & $\mathrm{U}^{+6}$ & Masked \\
\hline 27 & $\mathrm{Li}^{+1}$ & $1: 33$ \\
\hline 28 & $\mathrm{Na}^{+1}$ & $1: 35$ \\
\hline 29 & $\mathrm{~K}^{+1}$ & $1: 36$ \\
\hline 30 & $\mathrm{Mg}^{+2}$ & $1: 13$ \\
\hline 31 & $\mathrm{Ca}^{+2}$ & $1: 23$ \\
\hline
\end{tabular}




\section{H. Effect of divalent ions and foreign ions}

The effect of other ions present in various amount indicated no interference in the spectrophotometric determination of $5 \mathrm{ppm}$ of vanadium. The ions which show interference in the spectrophotometric determination of vanadium were overcome by using appropriate masking agents. (Table 2 and Table 3 )

Table 3. Observation Table For Masking Agents Used

\begin{tabular}{|c|c|}
\hline Interfering Ion & Masking agent \\
\hline $\mathrm{Ti}(\mathrm{IV})$ & Ascorbic acid \\
\hline $\mathrm{Fe}(\mathrm{III})$ & Sodium flouride \\
\hline $\mathrm{Cu}(\mathrm{II})$ & Sodium thiasulphate \\
\hline $\mathrm{U}(\mathrm{VI})$ & Oxine \\
\hline $\mathrm{Mo}$ (VI) & Citrate \\
\hline $\mathrm{EDTA}$ & Boiled with concentrated $\mathrm{HNO}_{3}$ \\
\hline $\mathrm{CN}^{-}$ & Boiled with concentrated $\mathrm{HNO}_{3}$ and formaldehyde \\
\hline
\end{tabular}

\section{Precision and accuracy}

The precision and accuracy of the developed spectrophotometric method have been studied by analyzing ten solutions each containing $4 \mu \mathrm{g}$ of vanadium in the aqueous phase. The average of ten determinations was 4.002 and variation from mean at 95\% confidence limit was \pm 0.0123 .

\section{J. Nature of extracted species}

The composition of extracted V (V): A24DHS complex has been determined by Job's continuous variation method. A Job plot is used to determine the stoichiometry of a binding event. In this method, the total molar concentration of metal ion and ligand are held constant, but their mole fractions are varied. A measurable parameter that is proportional to complex formation (such as absorption signal) is plotted against the mole fractions of these two components.

The maximum on the plot corresponds to the stoichiometry of the two species. This method is named after P. Job, who first introduced this methodology in 1928 [14]. It shows that the composition of $\mathrm{V}$ (V): A24DHS complex is 1:2 (Figure 4).

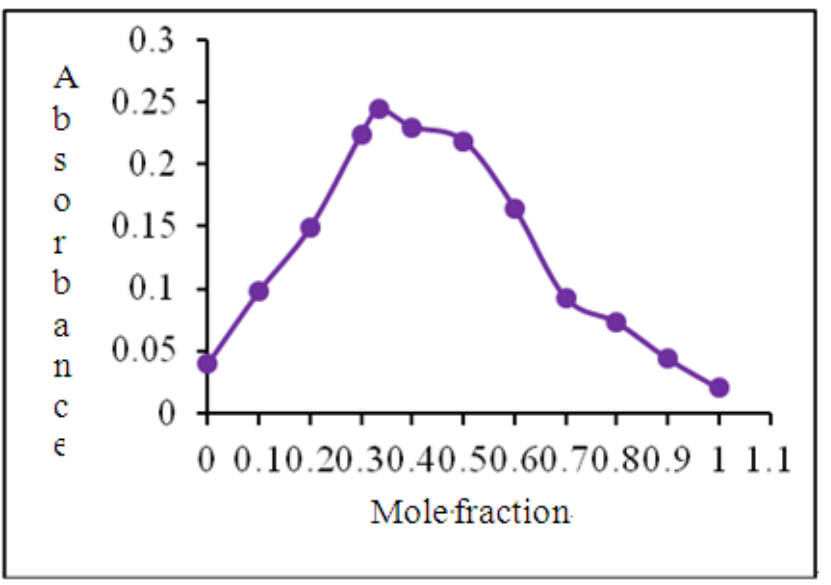

Figure 4. job’s continuous variation curve

\section{Applications}

The proposed method was successfully applied for the determination of Vanadium in various alloys and synthetic samples. The results are found to be in good agreement with those obtained by the standard known method. (Table 4).

\subsection{Determination of $V(V)$ in Alloys}

An accurately weighed amount of 0.3 / $0.5 \mathrm{~g}$ of alloy sample were dissolve in $25 \mathrm{~mL}$ of 1:4 sulphuric acid. When solution was completed, $5 \mathrm{~mL}$ of conc. $\mathrm{HNO}_{3}$ was introduced and boiled until nitrous fumes no longer evolved. The solution was diluted in $50 \mathrm{~mL}$ of hot water and then sat. potassium permaganate solution added until a pink color persists. Boiled for 5 minute. Add slight excess of sulphurous acid and boil off the excess. The solution was cooled. $5 \mathrm{~mL}$ orthophophoric acid and $5 \mathrm{~mL}$ of 10 volume hydrogen peroxide were added. Dilute the content to $100 \mathrm{~mL}$ and aliquot is used for the determination of Vanadium.

\subsection{Synthetic Mixtures}

The separation of Vanadium from synthetic mixture of associated metals containing Copper (II), zirconium (II), Cadmium (II), tungsten (II), zinc (II) and Molybdenum (VI) with varying combination was carried out. A definite aliquot of this solution was taken and after the adjustment of basicity of the aqueous solution to $\mathrm{pH} 8.2$ and addition of $2 \mathrm{~mL}$ of $0.1 \%$ A24DHS solution, formed vanadium complex was extracted into $10 \mathrm{~mL}$ of n-Butanol. Molybdenum was mask by using sodium citrate and copper by sodium thiasulphate. The amount vanadium was calculated using the calibration curve method. The result obtained is compared with those obtained by phosphotungstovanadate method.

Table 4. Determination of $\mathrm{v}(\mathrm{v})$ using a24dhs from different samples

\begin{tabular}{|c|c|c|c|}
$\begin{array}{c}\text { Sr. } \\
\text { No. }\end{array}$ & Sample & $\begin{array}{c}\text { Certified } \\
\text { value }\end{array}$ & $\begin{array}{c}\text { Present } \\
\text { method }\end{array}$ \\
\hline \multicolumn{4}{|c|}{ ALLOYS } \\
\hline 1 & Ferrovanadium & $0.250 \mu \mathrm{g}$ & $0.248 \mu \mathrm{g}$ \\
\hline 2 & $(\mathrm{~V}+\mathrm{Cr}+\mathrm{Ti})$ alloy & $0.240 \mu \mathrm{g}$ & $0.235 \mu \mathrm{g}$ \\
\hline \multicolumn{4}{|c|}{ SYNTHETIC MIXTURE } \\
\hline 2 & $\mathrm{~V}(100)+\mathrm{Cu}(100)+\mathrm{Zn}(100)$ & $99.99 \mathrm{ppm}$ & $99.98 \mathrm{ppm}$ \\
\hline 3 & $\mathrm{~V}(5)+\mathrm{Zr}(5)+\mathrm{W}(5)$ & $5.0 \mathrm{ppm}$ & $4.495 \mathrm{ppm}$ \\
\hline
\end{tabular}

1) Each result is average of three independent determinations.

2) Compared with Phosphotungstovanadate method.

\section{Conclusion}

Obtained results show that the newly developed method in which the reagent A24DHS was used, can be effectively used for quantitative extraction and estimation of $\mathrm{V}(\mathrm{V})$ from aqueous media. The result show good agreement with the standard method.

The developed method is compared with result obtained with the phosphotungstovanadate method for the estimation Vanadium and observed to be comparable. The method can be used even in small laboratories as it requires only UV - VISIBLE spectrophotometer and not much sophisticated and costly measurement devices or instrumentation.

\section{References}

[1] Weeks M. E.,' the discovery of the elements Columbium, tantalum and vanadium', J. Chem. Educ., 9, 863, 1932.

[2] Sjoberg S. G., 'Nils Gabriel Sefstrom and the discovery of vanadium’ J. Chem. Educ., 28, 294, 1951. 
[3] M. S. Vallarta and A. A. Y. Freg,' The Name of Element 23,' Nature, 160, 163, 1947.

[4] W. Rostoker, the Metallurgy of Vanadium, John Wiley and Sons, New York, 1958.

[5] Davis, Joseph R., Tool Materials: Tool Materials, ASM International, 1995.

[6] Khalid A. A., A. G. M. Al-Daher and Bashir W. A., 'Thiophene-2hydrazide as a reagent for the spectrophotometric determination of vanadium in aqueous solution' Analyst, 110, 409, 1985.

[7] Satyanarayana $\mathrm{K}$ and Mishra R K, 'Extraction-photometric determination of vanadium (V) with N-hydroxy-N-m-tolyl-N'-(2methyl-5-chloro) phenyl-p-toluamidine hydrochloride in the presence of acetic, monochloroacetic, and phenylacetic acids'; Anal. Chem., 46, 1609, 1974

[8] Kiss E.; 'Selective spectrophotometric determination of vanadium in silicates with a new pyridylazophenol in the presence of hydrogen peroxide’, Anal. Chim. Acta, 77, 205, 1975.
[9] Wilfred L. E Armarego, Christina Li Lin Chai, 'Purification of laboratory chemicals', 5th edi. Butterworth Heinemann, 2003.

[10] Ahluwalia V K., Bhagat P, Aggarwal R, Chandra R, 'Intermediates for organic synthesis', I.K. International Pvt. Ltd., 2005.

[11] Vogel A I, Textbook of Organic synthesis, 3rd ed., London, 1957, ELBS.

[12] Vogel A I, (1991), Textbook of Quantitative chemical analysis, 5th ed, London, ELBS, 690

[13] Skoog D A, Fundamentals of analytical chemistry, 8th ed., Thomson, 2004, chapt.8.

[14] Job, P. Ann. Chim. (1928) 9, 113-203.

[15] Janwadkar S.P., Lokhande R.S., Pitale S.M., 'Solvent extraction and spectrophotometric determination of Mo (VI) by using Acetophenone 2', 5'-dihydroxy semicarbazone' Int. J. of Pharma and Biosci. 3 (4), 309-314, 2011. 